\title{
The Impact of Humorous Movie Clips on Better Learning of English Language Vocabulary
}

\author{
Abolfazl Mahdiloo ${ }^{1} \&$ Siros Izadpanah ${ }^{2}$ \\ 1. Department of English Language Teaching, Zanjan branch, Islamic Azad University, Zanjan, Iran. \\ 2. Department of English Language Teaching, Zanjan branch, Islamic Azad University, Zanjan, Iran. \\ E-mail: cyrosizadpanah@yahoo.com
}

Received: March 13, $2017 \quad$ Accepted: May 2, $2017 \quad$ Online Published: June 20, 2017

\begin{abstract}
This study examined the effects of humorous movie clips on better learning of English language vocabulary. Humor is an important human behavior that plays a vital role in communication and social interactions. This subject has been rarely investigated in Iranian English classes. The researchers used quantitative method. Because all of variables were not controllable, therefore quasi-experimental method was employed to conduct the study. To this end, a proficiency test was administered to 60 Iranian EFL learners. Then 48 intermediate language learners who were homogeneous based on their rank scores were chosen and randomly divided into two equal groups (i.e. 24 as experimental and 24 as control groups). To assess their vocabulary knowledge at the beginning of the study, both groups participated in a researcher-made, 30-items and multiple choice vocabulary test adapted from PET test and scored out of 30. Experimental group watched the humorous movie clips but the participants in control group taught in a conventional way. After 10 sessions of treatment, both groups were tested on the similar items covered in the pre-test. The effect of humorous movie clips on the groups' vocabulary achievement was evaluated through Paired Samples $t$-test analysis. Results have shown that the experimental group outperformed the control group since humorous movie clips had a positive effect on developing vocabulary learning among intermediate EFL learners $(p<05)$ in the experimental group. EFL teachers can use humorous movie clips to raise the learners' motivation.
\end{abstract}

Keywords: Humor, humorous movie clip, vocabulary learning

\section{Introduction}

Humor is a complicated topic that has been examined by some of the greatest thinkers on the planet. It is a difficult concept to define or achieve, yet is a universal experience in daily life (Dehjalali \& Izadpanah, 2017; Earleywine, 2010), while simultaneously being subjective and highly personal (Garner, 2006). However, upon closer inspection, history shows a theoretical basis for humor, an examination of which may lead to other discoveries. As Freud points out, humor is strongly connected to other parts of the personality and surely helps us understand other facets (Shahlou \& Izadpanah, 2016).

Mayer and others focused on strategies to improve the crafting of multimedia content (Clark \& Mayer, 2016; Mayer, 2009). He defines a multimedia message as "a presentation involving words and pictures" (Mayer, 2009, p. 3) ranging from a narrated power point of static images to a full-motion video with sound. Mayer developed the Cognitive Theory of Multimedia Learning, building on Dual-Coding Theory (DCT), Cognitive Load Theory, and Active Learning (Moreno \& Mayer, 2007). DCT suggests that the mind receives and organizes verbal (words) and nonverbal (images) differently (Mayer, 2009; Ormrod, 2014), and that the visual and auditory input systems are different; thus, we see and hear information differently (Baddeley, 1992). Cognitive Load Theory suggests the mind has the capacity for a limited amount of information intake, which must be carefully managed (Chen \& Martin, 2007), while Active Learning proposes that the learner is an active participant in the learning process, taking in information and connecting it to previous learning (Mayer, 1999). 


\section{International Journal of Research in English Education}

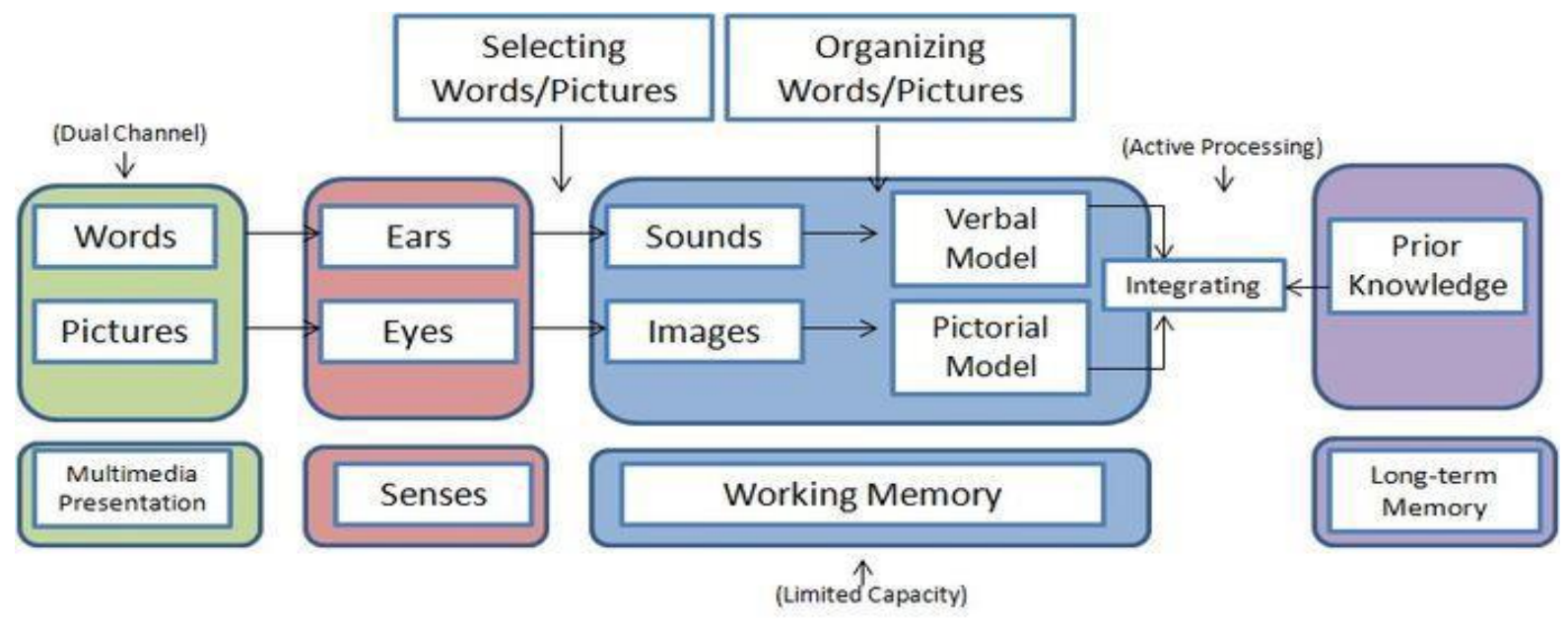

Figure 1. Mayer's cognitive theory of multimedia learning (Mayer, 2008)

These foundational theories provide the groundwork for specific strategies to design multimedia in a way that will improve the likelihood that information will be processed and connected to previous learning.

English Movie clips and films offer effective opportunities of audio activities for the progress of fluency. The important matter in using films and movies effectively depends on the teacher's ability to persuade students to receive the films` message. Some reasons for the use of films in English language teaching are (Askildson, 2005; Hoffler \& Leutner, 2007; Izadpanah \& Alavi, 2016; Schnotz, 2005):

- Movies are motivating and they help ease the cognitive load whereby learners can form mental images of the presented materials more comfortably.

- They enable learners to perform parallel cognitive processing by providing additional information that cannot be displayed through static pictures.

- They help learners build a dynamic mental representation by providing through external support for simulating the behavior of the system depicted. Iranian students and pupils from many other developing countries who study English as a foreign language do not have sufficient exposure to authentic materials in their schools.

Using humor in the English classes has been recommended to enhance educational effectiveness (Davies, 2003; Kher, Molstad, \& Donahue, 1999), increase message comprehension (Booth-Butterfield \& Wanzer, 2010), create an exciting and more comfortable classroom atmosphere (Jones, 2014; Neuliep, 1991), and progress student learning level (Baringer \& McCroskey, 2000; Gorham \& Christophel, 1990). The purpose of this study was to examine the role of humor on better learning of English language vocabulary.

\section{Significance of the Study}

The results of this study will add to the existing literature on the use of humor in instruction, ideally adding rigor to the experimental studies examining the effects on vocabulary learning. In addition, it will contribute to the perspective of humor in instruction designed for multimedia deployment. The English classroom can be an appropriate place to address L2 humor:

- Because many learners voice a desire for this humor.

- Because access to humor is frequently restricted for L2 speakers interacting with native speakers (NSs) outside of educational contexts.

- Because recent work in second language acquisition suggests that playful uses of language may facilitate second language learning (SLL). 


\section{International Journal of Research in English Education}

\section{Definition of Humor}

Mel Brooks wrote, "Tragedy is when I cut my finger. Comedy is when you fall into an open sewer and die" (Samson \& Gross, p. 125, 2012). The truthfulness of this statement and its absurdity at face value emphasizes that humor is hard to define, partially due to its association with individual perception. Funny people are never more uncomfortable than people argue that they "know what's funny when they see it" but cannot say why (Earleywine, 2010, p. 4). Defining humor and what is funny seems analogous to distinguishing between music and good music: it comes down to personal taste. Humor is "highly personal, subjective, and contextual and we cannot always predict the way it will be received, things that one person find humorous, ironic, or funny may be viewed by others as trite."(Garner, 2006, p. 178). Language teachers are often advised to use certain types of humor with learners of certain proficiency levels. For example, Butler-Pascoe and Wiburg (2003) divide humor into three categories, based on Long and Graesser's (1988) study:

1. universal humor,

2. culture-based humor, and

3. linguistic humor.

He claims that elementary-level students can benefit from the use of the first type, intermediate students will appreciate universal humor plus some types of culture-base jokes, and advanced students can benefit from and appreciate all three types. Wagner and Urios-Aparisi (2011) stated wordplay is an example of a type of humor that is often cited as difficult and best reserved for those of advanced proficiency (Berwald, 1992; Deneire, 1995; Rawlings, 2013).

\section{Universal vs. Culture-based Humor}

The distinction between humor with a broad cross-cultural appeal, called 'universal humor' by many scholars, and humor that requires culture-specific knowledge to understand and appreciate is often presented in articles providing recommendations for pedagogical uses of humor (Ketabi \& Simm, 2009).

Four main reasons exist to take advantage of the humor that occurs in the classroom and to encourage its creation and discussion:

1. Student's wants, needs, and goals.

2. Nature of the classroom itself as a site for experimentation.

3. Complexity of humor.

4. Potential of humor to facilitate language acquisition.

Lier (2007) found that humor has had many definitions and means something different from jokes, mirth, or laughter, as in the past the word "humor" was equated with mood.

\subsection{Theories of Humor}

For centuries, the enigma of humor has confounded great thinkers and scholars making them to formulate theories to deepen our understanding of this phenomenon. Historically, the classical theories namely: psychoanalytic theory, superiority/disparagement theory, incongruity theory, and arousal theory have been the theories scholars have propounded to elucidate the phenomenon. Indeed, Clark (2013) intimates that the classical theories of humor constitute the seminal work which forms the conceptual foundation upon which humor scholarship in all disciplines are built. Also, organizational humor researchers have mostly drawn on these primary theories of humor in their studies (Ziyaeemehr, Kumar, \& Abdullah, 2011).

\section{Freud's Psychoanalytic Theory of Humor}

Many psychoanalytic theories abound in the literature but this perspective of humor research was popularized by Sigmund Freud in the 1900s. His theory appears to have spawned the others (Berger, 1987). The major premise of this theory is that humor, being a sophisticated phenomenon, helps in disguising playful aggression. In building this theory, Medgyes (2002) drew on Filipowicz (2006) to explain the object of laughter. He proffered that if excess energy builds up in the nervous system, it has to be dissipated and the only means for this excess energy to be shed was through laughter. In explaining laughter, Freud delineated three kinds of phenomena attributable to laughter: wit or jokes, 


\section{International Journal of Research in English Education}

humor (in the narrow sense) and comic. Jokes, according to Freud (1960), distracts our conscience allowing for a momentary expression and enjoyment of aggressive signals. The repressive energy which would otherwise have inhibited these aggressive drives becomes surplus. It is this surplus energy that comes out as laughter. Thus, jokes feel enjoyable because of the satisfaction derived from the innate playful stimuli (Shahlou \& Izadpanah, 2016).

The humor aspect of laughter becomes evident in instances when people experiencing negative emotion, arising from an unpleasant situation, suddenly perceives hilarious or ambiguous aspects of the situation. They laugh at their own blunders or misfortune to help them stop experiencing this negative emotion. Finally, Freud (1960) explained the comic aspect as the non-verbal source of amusement. In this context, an observer in anticipating an event to happen mobilizes some form of mental energy to process the event. This mental energy becomes redundant when the anticipated condition does not occur which is released in the form of laughter (Martin, 2007). For example, a person watching a clown walk a tight rope expects him to walk to the end of the rope. However, if the clown is not able to make it and falls midway, the expectant spectator may burst into laughter to shed the built up excess mental energy.

In analyzing the psychoanalytic theory, it reveals two major drawbacks. First, numerous researches have been conducted to test the hypotheses of this theory. The results, unfortunately, have been inconclusive and inconsistent. Second, the redundant energy-laughter premise on which the theory was built has been found not to be consistent with modern understanding of the nervous system. This has led to the abandonment of the psychoanalytic theory by most empirical researchers. Even though this theory appears not to adequately explain all aspects of humor, it brought to the fore relevant aspects of humor like aggression and sexual themes inherent in most jokes and also the emotional satisfaction derived from humor (Berger, 1987; Dehjalali \& Izadpanah, 2017; Martin, 2007).

\section{Previous Studies about the Positive Effects of Humor on Learning}

In 2012, Chua Yan Piaw from University of Malaya, Malaysia studied about using content-based humorous cartoons in learning materials in order to improve students reading rate, comprehension, and motivation. For this purpose, researchers used a between subject repeated-measures experimental method and also follow-up survey study. Participants of this study were 80 teachers selected from Teacher Training Centre in Malaysia with the almost same educational background. Instruments of the study were course materials, reading comprehension test, and reading motivation questionnaire. Split-plot ANOVA tests administered to analyze the data for showing the effects of illustration on reading comprehension and motivation. Results showed that illustrations had considerable effects on comprehension and motivation of the learners.

In 2014, Fatemi, Motallebzade, and Motlagh studied about the effects of teachers' sense of humor on learners reading comprehension ability. They believed that teachers' sense of humor has miracle role in creating effective educational atmosphere. They administered Nelson proficiency test to homogenize participants of the study. So 58 participants were selected out of 100 male intermediate learners in Shiraz, Iran and divided them into two groups: an experimental group which received the lessons through well-defined humorous condition managed by the teacher, and control group that received lessons in normal manner. The researchers used humor questionnaire and TOEFL sample test to choose instructors of this study. For this purpose, the teacher who got highest grade in humor questionnaire was chosen for teaching to experimental group and the person who got lowest grade on questionnaire was chosen for teaching to control group. Their study strongly revealed that the appropriate level of teacher's sense of humor has positive effects on learners' reading comprehension.

According to Mekheimer's (2011) research, it was indicated that exposure to supplementary video material can be beneficial to whole language development. This study was set to measure improvement gains in aural/oral, reading, and writing skills using data from an experiment that was conducted over a period of one academic year. Following an intensive, concentrated exposure to authentic video material accompanying a language skills development remedial program and extensive videos of some selected dramatized famous literary works, participants in an experimental group $(n=33)$ demonstrated statistically significant gain scores over their peers in the control group ( $n=31)$ across all skills. The research discovered that authentic video, inducing satisfactory viewing comprehension as well as presented in an integrated language skills instruction, is a valuable approach to whole language teaching.

Luo (2004) examined the influence of DVD movies on students' listening comprehension. Nine films were incorporated into the class curriculum over the entire school year. The DVDs were the main materials of the course, supported by specially designed additional activities. Instructional activities included storytelling, picture description, 


\section{International Journal of Research in English Education}

and open-ended questions for group discussion on topics retrieved from the movies. The researchers incorporated caption-on and caption-off activities in order to practice student's listening skills. The final results of the statistical analyses indicated that student's listening skill "did improve" through the instruction of using DVD movies in a motivating learning environment with "lower level of anxiety" after a whole school year.

\subsection{Previous Studies about the Ineffectiveness of Humorous Movie Clips on Vocabulary Learning}

While the studies just described focused on positive outcomes, other studies show no improvement in learning. For example, in a study done with students in a professional speaking class, Gruner (1967) randomized students and played them an audio speech. Two sections of a class were randomized into four groups with the same two conditions: the control group $(n=64)$ heard the speech without humor, and the experimental group $(n=64)$ heard the speech with additions of selected humor. Gruner added four humorous items in the introductory paragraph of the speech and three more in the second paragraph. He added five additional items evenly through the rest of the speech (the length of the speech was not specified). Gruner measured learning with a 25 -item multiple-choice test, whose validity he ensured via a panel. He found no significant difference in their retention scores.

Gruner's study was well-designed. He took additional precautions, including using a panel to determine relatedness of learning assessments, and ensured that the experimental version of the speech was perceived as more humorous with a bipolar instrument. Limitations of the study include the lack of specificity about the type of humor and its relation to the content.

Gruner did an additional study with the same speech $(n=144)$, this time with four conditions: humorous-interesting, serious-interesting, humorous-dull, and serious-dull (Aria \& Izadpanah, 2017; Gruner, 1970). Interesting was defined by the Flesch Human Interest scale. Twenty-two humorous items were added to the speech, and the interesting speech was recorded with an enthusiastic voice, the dull speech with a monotone voice. Students found the serious-interesting speech the most interesting, and more interesting than the interesting-humorous speech. Gruner found that learning improved along interest but not along humor lines (Gruner, 1970; Nazarian \& Izadpanah, 2017). The limitations described in the review of this study in the Instructor Evaluations section above apply to the learning results as well: since the dull speeches were performed differently than interesting speeches, this may have created a confounding variable, an idea pointed out by Mayer in the Voice Principle (Mayer, 2009).

\subsection{Previous Studies about the Negative Effects of Humor on Learning}

One study found that humor negatively affected learning. In a study performed on visitors to a planetarium, Fisher added a single line of humor to 10 of 20 concepts in a recorded presentation (Fisher, 1997). Participants (n=495) were visitors to the planetarium over the age of 18 with a wide demographic background. After a 5-minute live introduction, he showed humorous and non-humorous versions of a 15-minute pre-recorded presentation. Humorous additions were added roughly every 90 seconds. For example, when pointing out Saturn with the planetarium's pointer, the narrator added, "You won't see this arrow in the sky outside. Trust me," (Fisher, 1997, p. 708). The non-humorous version had silence in the place of the humorous additions. Immediately after the presentation participants took a 20 -item test based on the non-humorous script of the presentation. Participants who watched the non-humorous presentation $(\mathrm{n}=250$, mean=13.6) scored slightly but significantly higher than those who watched the humorous presentation $(n=245$, mean=12. 8). Fisher postulates that too much humor may have been added, or at too fast a pace, confusing the audience. This connects to the ideas of careful use of humor to avoid distraction, as suggested earlier, signifying that a moderate approach may be most successful (Earleywine, 2010; Mayer, 2014).

Previous studies have shown mixed results in terms of learning gains, with the most rigorous studies showing no significant difference between learning environments incorporating humor and those that do not (Fisher, 1997; Gruner, 1967). This study seeks to improve on many of the existing studies by incorporating a more rigorous experimental approach. Finally, studies focusing on the effects of humor on English language learning have largely used multimedia as a means of capturing static lecture material. 


\section{International Journal of Research in English Education}

\section{Method}

\subsection{Design}

In this study, the researchers used quantitative method, pre-test, intervention (treatment), post-test to investigate the issue of humorous video clip impacts and learners' vocabulary learning in the EFL classroom. Because the researchers could not control all independent variables, therefore quasi-experimental method was employed to conduct the study.

\subsection{Participants}

The participants of this study were 70 Iranian intermediate EFL learners studying at Jahade-Daneshgahi Institute, East Azerbaijan, Miyaneh branch. Based on Cochran formula, 60 of them were chosen from 70 as the convenience sampling participants of this study. They were selected among both males and females, approximately aged from 16 to 22. The participants were chosen among the learners who had been placed at the intermediate level based on the institute's placement test. While the data were collected, they studied Top Notch 2 book and their English classes hold three times a week.

Sixty Iranian intermediate EFL learners took a Nelson Proficiency Test section of vocabulary. Before tests, they were persuaded that their performance on the tests would be calculated as part of their class activity. This encouraged them to participate more seriously in the experiments. This test aimed to match the participants and make them more homogenized. Among them, the scores of 48 students were located one standard deviation below and above the mean (+/-1 SD), and consequently were considered to be roughly at the same vocabulary proficiency level. These learners were served as the participants of this study. Also, two teachers who were willing to participate in this study were selected as instructors.

These selected participants were assigned to two groups, namely, experimental group exposed to video which accompanied humor $(n=24)$ and control group taught conventionally $(n=24)$. Then, after data collection, the performance of both groups was submitted to statistical analyses for further analysis.

\subsection{Instruments}

In this research, four instruments were utilized:

1. Nelson Proficiency Test

2. Vocabulary test adapted from the PET test as a pre-test

3. Humorous video clips (adapted from "FRIENDS" serial)

4. Vocabulary test adapted from the PET test as a post-test

The data were collected through pre-test, intervention (treatment), post-test, and a five-scale Likert motivation questionnaire response.

\subsection{Nelson Proficiency Test}

The researchers shortened the Nelson Proficiency Test, multiple-choice test comprised 50 items ranging from cloze passages, vocabulary, structure, and pronunciation, to 20 questions including vocabulary and reading questions in paper-and-pencil format and scoring system was from twenty (each question = one point). To check the reliability of the test after adoption, first 10 learners who were similar to the target group took the test for the first time and after 15 days again they were given the same test (See Table 1). The Cronbach's Alpha of the two tests was .851 that showed the test was reliable enough to be used in our study according to our context (See Table 2).

Table 1. Reliability statistics of Nelson Proficiency Test

\begin{tabular}{ll}
\hline Cronbach's Alpha & N of Items \\
\hline .851 & 2 \\
\hline
\end{tabular}




\section{International Journal of Research in English Education}

Table 2. Validity statistics of Nelson Proficiency Test

\begin{tabular}{llll}
\hline & & $\mathrm{N}$ & $\%$ \\
\hline Cases & Valid & 10 & 100.0 \\
& Excluded $^{\mathrm{a}}$ & 0 & .0 \\
& Total & 10 & 100.0 \\
\hline
\end{tabular}

\subsection{Vocabulary Test Adapted from PET Test as a Pre-test}

Researcher-made vocabulary test adapted from the PET test accompanied by the lexicals of the research's clips (15 questions from PET and 15 questions from research humorous movies). Words were selected from the "Friends" serial. After that those thirty questions were distributed among 20 learners to estimate its Internal Reliability, and Cronbach's Alpha was 0.91 indicating that all items were reliable; no items out of 30 vocabulary questions were excluded. (Tables $3 \& 4$ ). The scoring system was out of 30 .

Table 3. Reliability statistics of PET test

\begin{tabular}{ll}
\hline Cronbach's Alpha & N of Items \\
\hline .914 & 2 \\
\hline
\end{tabular}

Table 4. Validity statistics of PET test

\begin{tabular}{llll}
\hline & & $\mathrm{N}$ & $\%$ \\
\hline Cases & Valid & 20 & 100.0 \\
& Excluded $^{\mathrm{a}}$ & 0 & .0 \\
& Total & 20 & 100.0 \\
\hline
\end{tabular}

a. Listwise deletion based on all variables in the procedure.

\subsection{Treatment: Humorous Video Clips Adapted from “FRIENDS” Serial}

As the researchers indicated before, 15 instructional humorous movie clips were shown to the experimental group during 10 sessions, each session 15 minutes discussion and explanation about the vocabulary and its synonyms. The short movies were numbered by the researchers from 1 to 15 to avoiding mess. They also transcript them into written as a list below:

1. Hang out: spending time together a lot,

2. Make fun of something: fool something,

3. A) My mistake: I'm sorry. B) Dear Lord: Oh my God,

4. To be based on: to rely on,

5. A) Someone is into me: someone loves me. B) Set someone up: set an appointment for someone,

6. A) No way: don not have any remedy. B) Pretend: to show interest,

7. Cranky: mad,

8. It doesn't matter: no problem,

9. Rough: hard, 


\section{International Journal of Research in English Education}

10. Gossip: false statements about someone,

11. What the hell is wrong with you: what happens to you,

12. To baby-sit: look after baby,

13. Embarrassing: causing shame,

14. That's so unfair: injustice, and

15. Don't be such a baby: be serious

\subsection{Post-test}

A multiple-choice post-test was designed by the researchers to test the immediate results of the proposed method of vocabulary teaching administered among participants. This test contained 30 multiple-choice items. The post-test was done to determine the effects of using pedagogical films on vocabulary learning. Moreover, post-test includes the almost same question in the pre-test (in some questions researchers used from the pre-test words synonyms) in order to avoiding pre-test direct effects. Four options were provided for each item from among which students selected the correct one. Reliability of the test was assured by piloting and comparing with standard PET vocabulary test (Cronbach's Alpha=.92). Multiple-choice items were aimed at checking whether the students learned the meaning of the vocabularies or not.

Table 5. Reliability statistics of post-test

\begin{tabular}{ll}
\hline Cronbach's Alpha & N of Items \\
\hline .927 & 2 \\
\hline
\end{tabular}

Table 6. Validity statistics of post-test

\begin{tabular}{llll}
\hline & & $\mathrm{N}$ & $\%$ \\
\hline Cases & Valid & 20 & 100.0 \\
& Excluded $^{\mathrm{a}}$ & 0 & .0 \\
& Total & 20 & 100.0 \\
\hline
\end{tabular}

\subsection{Procedure}

Initially, the participants were justified about the research procedures. Then adapted Nelson Proficiency Test was administered to homogenize the participants. Consequently, 48 participants that their scores were located one standard deviation below and above the mean (+/-1 SD) were served as the participants of this study. The reliability of this test measured through test-retest way; therefore, correlation of the two tests was 0.05 that showed the test was reliable enough. In the following session, researcher-made vocabulary test adapted from the PET test accompanied by the vocabularies of the research's clips (15 questions from PET and 15 questions from research humorous movies) was administered as a pre-test after piloting. The required time for the completion of the pre-test was between 20 to 30 minutes. After ten sessions treatment, every session two humorous clips was shown to participants of experimental group (meanwhile control group got conventional ways of teaching and evaluating), and 15 minutes explanation around the clip, the researchers administered the post-test, which is adapted from PET test accompanied by the vocabularies of the research's clips.

\section{Results and Analysis}

To data analysis, Paired T-test analyses were used to see the relationship between humorous video clips and the learners' vocabulary learning by SPSS18. To test the research hypothesis, the researchers dealt with comparing two groups based on the role of watching instructional humorous movie clips in vocabulary learning. To do so, students' 


\section{International Journal of Research in English Education}

vocabulary test was conducted at the first and the end of the study period as the pre-test and post-test of vocabulary learning.

The analysis went further to find out whether it affects on students' performance in vocabulary test; two $t$-test analyses were applied in this section for two groups' performances on vocabulary test. Then a Paired Samples t-test was also performed to determine the rate of mean differences, if any, between two groups and this last $t$-test was used to show the role of watching humorous movie clips on vocabulary learning. It is important to note that the researchers employed all the formulas with the level of significance set at 0.05 in all their applications. Table 7 provides the descriptive statistics of students' vocabulary pre-test in terms of the number of participants $(\mathrm{N})$, means, standard deviations (SD), and standard errors of mean.

Table 7. Group statistics (Pre-tests of vocabulary, experimental vs. control groups)

\begin{tabular}{lllll}
\hline Pre-test of vocabulary & $\mathrm{N}$ & Mean & Std. Deviation & Std. Error Mean \\
\hline Control & 24 & 17.37 & 4.50 & 0.92 \\
experimental & 24 & 18.00 & 5.16 & 1.05 \\
\hline
\end{tabular}

According to the Table 7, the mean scores of pre-test for the control group and the experimental group were 17.37 and 18.00 respectively. Descriptive statistics of students' vocabulary post-test are summarized in the Table 8 .

Table 8. Group statistics (Post-tests of vocabulary, experimental vs. control groups)

\begin{tabular}{lllll}
\hline Post-test of vocabulary & $\mathrm{N}$ & Mean & Std. Deviation & Std. Error Mean \\
\hline Control & 24 & 18.62 & 4.37 & 0.89 \\
Experimental & 24 & 22.20 & 4.70 & 0.96 \\
\hline
\end{tabular}

The mean scores of post-test were 18.62 for the control group and 22.20 for the experimental group. Table 9 provides descriptive statistics of both pre and post-tests of students' vocabulary.

Table 9. Descriptive statistics (Pre and post-tests of vocabulary)

\begin{tabular}{llllll}
\hline & N & Minimum & Maximum & Mean & Std. Deviation \\
\hline Pre-test control & 24 & 11.00 & 28.00 & 17.37 & 4.50 \\
Post-test control & 24 & 13.00 & 30.00 & 18.62 & 4.37 \\
Pre-test experimental & 24 & 10.00 & 28.00 & 18.00 & 5.16 \\
Post-test experimental & 24 & 13.00 & 30.00 & 22.20 & 4.708 \\
Valid N & 24 & & & & \\
\hline
\end{tabular}

The results showed that the pre-test vocabulary scores ranged from 11 to 28 out of 30 in the control group and 10 to 28 out of 30 in the experimental group. Also, the scores of post-test speaking ranged from 13 to 30 in the control group and 13 to 30 in the experimental group. According to Table 3, the mean scores of the experimental group ( $M=18$, $\mathrm{SD}=5.16)$ were approximately similar to those of the control group $(\mathrm{M}=17.37, \mathrm{SD}=4.50)$ in pre-test, but the above table shows that the mean scores of the experimental group in post-test $(\mathrm{M}=22.20, \mathrm{SD}=4.70)$ were significantly different from those of control group $(\mathrm{M}=18.62, \mathrm{SD}=4.37)$. The results of the $\mathrm{t}$-test of pre-test in both groups is summarized in Table 10. 
Table 10. Paired Samples t-test (Pre-tests of vocabulary, experimental vs. control groups)

Paired Differences

\begin{tabular}{|c|c|c|c|c|c|c|c|c|}
\hline & \multirow[b]{2}{*}{ Mean } & \multirow{2}{*}{$\begin{array}{l}\text { Std. } \\
\text { Deviation }\end{array}$} & \multirow{2}{*}{$\begin{array}{l}\text { Std. Error } \\
\text { Mean }\end{array}$} & \multicolumn{3}{|c|}{$\begin{array}{l}95 \% \text { Confidence Interval } \\
\text { of the Difference }\end{array}$} & \multirow[b]{2}{*}{$\mathrm{df}$} & \multirow[b]{2}{*}{ Sig. (2-tailed) } \\
\hline & & & & Lower & Upper & $\mathrm{t}$ & & \\
\hline Pre-test Control & - & & & & & & & \\
\hline $\begin{array}{l}\text { Pre-test } \\
\text { Experimental }\end{array}$ & -.62 & 7.15 & 1.46 & -3.64 & 2.39 & -.42 & 23 & .67 \\
\hline
\end{tabular}

According to pre-tests of Paired Samples Test (Table 10), observed $t(-0.42)$ was less than critical $t$ (2.066) with df 23 in pre-tests. Furthermore, $t$-test analysis shows significance value as 0.67 which is much greater than 0.05 . This means that there is no statistical significance between mean performances of the two sets of scores in experimental and control groups in the pre-test; therefore, it can be claimed that two groups were homogeneous at the beginning of the experiment regarding their prior knowledge. Table 11 shows the results of the $t$-test of the post-test in both groups.

Table 11. Paired Samples t- test (Post-tests of vocabulary, experimental vs. control groups

Paired Differences

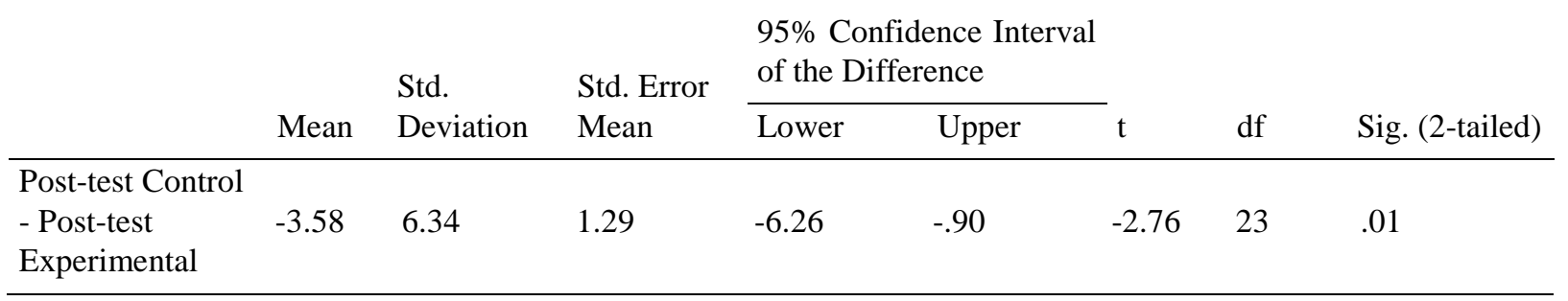

As presented in Table 11, the observed $t(-2.76)$ was greater than critical $t$ (2.066) with df 23. Also, computed significance equals 0.01 which is smaller than the significance level set for the study (0.05). Based on the results obtained, this strategy improved students' vocabulary learning. Hence, the second null hypothesis was rejected due to the greater value of the means and higher amount of observed $t$ than critical $t$. This substantiated the fact that there was a statistically significant difference between the experimental and the control groups confirming the effect of humorous films on the EFL learners' vocabulary knowledge. As shown in the Tables 10 and 11 , there were considerable individual differences in vocabulary before and after the treatment. In other words, the experimental group outperformed the control group on the post-test and this means that the hypothesis was rejected. It proves that the treatment has increased vocabulary test scores. In other words, humorous short films have significant effects on a vocabulary test scores.

\section{Discussion}

The hypothesis of the study was as follows: Humorous movie clips do not influence on better learning of English language vocabulary.

What is perhaps most impressive is the significant difference in performances of a humorous group than conventional group about vocabulary learning, so our hypothesis was rejected. Concerning the integration of videos in teachinglearning English, classroom tests revealed that intermediate EFL learners appreciate learning with videos and consider them very interesting and more encouraging since they want to learn with new strategies that go with their life style especially with the development of technology. In addition, they stated that they feel more at ease when learning with a video; it motivates them to participate and express themselves without the fear to be wrong. Videos facilitate learners' 


\section{International Journal of Research in English Education}

understanding of the subject matter. Students do not only listen to the language, but they see it as well. Through watching videos, they can easily decode the meaning through the assistance of pictures and sounds even if they do not necessarily understand all what the speaker says.

Since the experimental groups outperformed the control groups in post-test, teaching vocabulary through humorous video clips are supposed to improve vocabulary knowledge among intermediate EFL learners. One possible explanation of such a result is that the correct use of video clips in the classrooms may help students to enhance their vocabulary level. This explanation is compatible with Aria and Izadpanah (2017) and Cann and Zapata (2011) who discovered that films could be used as the major course materials in listening and speaking courses for English majors at the university levels. It also showed that students benefited from using films.

There is almost a complete lack of literature to be discussed aligned with the present findings. Among very few studies, the results of this study can be compared with those of other studies that have examined the effect of other methods on L2 learners` vocabulary learning. For example, regarding the research question, the results of this study are in tune with those of Secules et al. (1992), and Bahrani and Soltani (2011). In their studies, which was conducted on L1 learners, they used video films and movie clips in order to enhance the learner's vocabulary and idiomatic structures. By analyzing the collected data, they concluded that by using video films and instructional movie clips, the participants made progress in their vocabulary and idiomatic structures.

Tabatabaei and Gahroei (2011) and Ghaderi and Afshinfar (2014) showed the effective role of movie clips in idiom teaching and learning. Chun and Plass (1996) assert that if words and idioms are presented along with actual objects or imagery techniques such as pictures and videos, higher degree of absorption and retention is achievable.

The results of the present study, though preliminary in nature, would seem to strongly support many of the beneficial effects of pedagogical humor in the language classroom as described in the previous literature reviewed above. The overwhelming majority of those surveyed indicated that even general (nontarget language) humor was an important element of creating an overall environment conducive to learning. Specifically, participants indicated reduced anxiety/tension, improved approachability of teachers, and increased levels of interest as a result of humor usage by the teacher. This was true for both student and teacher respondents and thus creates a powerful indicator of perceived effect of humor usage in the classroom. While some of these perceived benefits to humor may be couched within larger frameworks of immediacy behaviors, it seems quite evident that students and teachers view such effects of humor as sufficiently significant in and of themselves. Clearly then, humor is perceived as an important component for the learning process among both students and teachers and must, therefore, be given consideration in the evaluation of pedagogical approaches to language teaching.

In addition, student participants indicated a very strong perception of increased language and cultural learning resulting from the employment of targeted linguistic humor in the target language. These results of perceived language acquisition and cultural transmission through the use of TL humor (in the form of jokes, puns, funny anecdotes, etc.) correspond with the findings of Deneire (1995), Trachtenberg (1979), and others. The implications for such a gain in linguistic and cultural acquisition through humor usage are significant to pedagogical planners and offer a componential medium for the transmission of TL linguistic and cultural patterns in a novel and engaging format. Nonetheless, hard empirical data (en lieu of perceptual evidence) in support of such pedagogical humor is lacking. Indeed, while major studies of the effects of general affective humor abound in pedagogical and psychological research, no large-scale quantitative research has been carried out to address such targeted linguistic humor - that is, linguistic humor employed in the TL with the intention of illustrating specific TL features. Indeed, future research is particularly needed in order to examine language learning gain and retention among learners presented with such targeted linguistic humor.

This study suffered from the lack of non-humorous movie clips that contained similar content. So replications of this study employing different conditions with typical type of movie clips that teach the same words could enhance this generalizability. Time for the implementation of this experiment was too short; maybe implementing this method over more periods of time may yield different findings. The study was limited to a relatively low number of students. Another limitation of the research was the impossibility to establish to what extent the videos shown in the classroom influenced the pupils' language skills, in comparison with the videos they watched outside of school. 


\section{International Journal of Research in English Education}

\section{Conclusion}

Humor has been shown to improve perception of the instructor, improve perception of the classroom environment, and has mixed effects on student learning. This may indicate that their positive experience of humor improved their learning. The outcome of this study substantiates the fact that experimental group learners were able to enhance their vocabulary knowledge and humorous movie clips have a moderately large effect on their vocabulary test scores. The difference between participants' scores in post-test and pre-test was significant enough and therefore humorous movie clips have impact on participants' vocabulary learning.

The following conclusions can be drawn from the present study. The major finding was that showing humorous movie clips in the English language classes was very useful and led to better vocabulary learning. Therefore, it can be argued that watching the humorous movie clips facilitated the development of the vocabulary knowledge of the students. Overall, our study supported the belief that most vocabulary is learned from context (Sternberg, 1987). This study might have provided evidence to the assumption that incidental or indirect learning of vocabulary can be achieved by resorting to contextual cues (Duquette \& Painchaud, 1996). This calls for an important pedagogical implication for teacher about using contextual communication materials to assist students' vocabulary learning instead of explaining the words in an isolated manner. The development that was observed in vocabulary knowledge supported the idea that vocabulary acquisition is a process that occurs along a continuum (Paribakht \& Wesche, 1996; Schmidt, 2001).

\section{References}

Aria, M. R., \& Izadpanah, S. (2017). The influence of Weblog on Iranian intermediate EFL learners' attitude towards writing. Modern Journal of Language Teaching Methods, 7(3), 64-69.

Askildson, L. (2005). Effects of humor in the language classroom: Humor as a pedagogical tool in theory and practice. Arizona Working Papers in SLAT, 12(1), 45-61.

Baddeley, A. (1992). Working memory. Science, 255(5044), 556-601.

Bahrani, T., \& Soltani, R. (2011). The pedagogical values of cartoons. Research on Humanities and Social Sciences, l(4), 19-22.

Baringer, D. K., \& McCroskey, J. C. (2000). Immediacy in the classroom: Student immediacy. Communication Education, 49(2), 178-186.

Berger, J. (1987). Notes on using video in the language classroom. If you can read this, thank TV. TESOL Journal, 6(2), 15-18.

Berwald, J. P. (1992). Teaching French language and culture by means of humor. French Review, 189-200. URL: http://www.jstor.org/stable/397569

Booth-Butterfield, M., \& Wanzer, M. B. (2010). Humor and communication in instructional contexts: Goal-oriented communication. The SAGE handbook of communication and instruction, 221-239.

Butler-Pascoe, M. E., \& Wiburg, K. M. (2003). Technology and teaching English language learners. MA: Pearson Education. http://dx.doi.org/10.1300/J025v20n01_09

Cann, A., Davis, H. B., \& Zapata, C. L. (2011). Humor styles and relationship satisfaction in dating couples: Perceived versus self-reported humor styles as predictors of satisfaction. Humor-International Journal of Humor Research, 24 (1), 1-20. doi: https://doi.org/10.1515/humr.2011.001

Chen, G. H., \& Martin, R. A. (2007). A comparison of humor styles, coping humor, and mental health between Chinese and Canadian university students. Humor-International Journal of Humor Research, 20(3), 215234. doi: https://doi.org/10.1515/HUMOR.2007.011

Chua, Y. P. (2012). Using content-based humorous cartoons in learning materials to improve students' reading rate, comprehension and motivation: It is a wrong technique? Procedia - Social and Behavioral Sciences, 64, 352361. https://doi.org/10.1016/j.sbspro.2012.11.042

Chun, D. M., \& Plass, J. L. (1996). Effects of multimedia annotations on vocabulary acquisition. The Modern Language Journal, 80(2), 183-198. 


\section{International Journal of Research in English Education}

Clark, C. D. (2013). Books worth (re-) reading: The act of creation by Arthur Koestler (1969). International Journal of Play, 2(3), 297-300. http://dx.doi.org/10.1080/21594937.2013.849138

Clark, R. C., \& Mayer, R. E. (2016). E-learning and the science of instruction: Proven guidelines for consumers and designers of multimedia learning. John Wiley \& Sons. doi: 10.1002/9781119239086

Davies, C. E. (2003). How English-learners joke with native speakers: an interactional sociolinguistic perspective on humor as collaborative discourse across cultures. Journal of pragmatics, 35(9), 1361-1385. https://doi.org/10.1016/S0378-2166(02)00181-9

Dehjalali, M. R., \& Izadpanah, S. (2017). The study of vocabulary awareness effect on intermediate language learners' depth of vocabulary knowledge in Genuine Persian texts. International Journal of English Linguistics, 7(1), 185-191. doi: https://doi.org/10.5539/ijel.v7n1p185

Deneire, M. (1995). Humor and foreign language teaching. Humor, 8, $285-285$. doi: https://doi.org/10.1515/humr.1995.8.3.285

Duquette, L., \& Painchaud, G. (1996). A comparison of vocabulary acquisition in audio and video contexts. The Canadian Modern Language Review, 54(1) 143-172.

Earleywine, M. (2010). Humor 101. Springer Publishing Company.

Filipowicz, A. (2006). From positive affect to creativity: The surprising role of surprise. Creativity Research Journal, 18(2), 141-152. http://dx.doi.org/10.1207/s15326934crj1802_2

Fisher R. (1997). Games for thinking. Oxford: Nash Pollock.

Freud, S. (1960). Jokes and their relation to the unconscious (J. Strachey, Trans.). New York: W. W. Norton.

Garner, R. L. (2006). Humor in pedagogy: How ha-ha can lead to aha!. College Teaching, 54(1), 177-180. http://dx.doi.org/10.3200/CTCH.54.1.177-180

Ghaderi, V., \& Afshinfar, J. (2014). A comparative study of the effects of animated versus static funny pictures on Iranian intermediate EFL students' intake and retention of idioms. Procedia-Social and Behavioral Sciences, 98, 522-531. https://doi.org/10.1016/j.sbspro.2014.03.448

Ghanei Motlagh, F., Motallebzade, K., \& Fatemi, M. A. (2014). On the effects of teacher's sense of humor on Iranian's EFL learners' reading comprehension ability. International Journal of Applied Linguistics \& English Literature, 3(4), 1-5. doi: http://dx.doi.org/10.7575/aiac.ijalel.v.3n.4p.1

Gorham, J., \& Christophel, D. M. (1990). The relationship of teachers' use of humor in the classroom to immediacy and student learning. Communication Education, 39(1), 46-62.

Gruner, C. R. (1967). The effect of humor on speaker ethos and audience information gain. J. Commun, 17, $228-233$.

Gruner, C. R. (1970). The effects of humor in dull and interesting informative speeches. Cent. States Speech J. 21, 160-166.

Höffler, T. N., \& Leutner, D. (2007). Instructional animation versus static pictures: A meta-analysis. Learning and Instruction, 17(6), 722-738. https://doi.org/10.1016/j.learninstruc.2007.09.013

Izadpanah, S., \& Alavi, M. (2016). The perception of EFL high school students in using of computer technology in the process of learning: merits and demerits. Advances in Language and Literary Studies (ALLS), 7(3), 146156. URL: http://dx.doi.org/10.7575/aiac.alls.v.7n.3p.146

Jones, G. H. (2014). Humor to the rescue: how to make introductory economics an appealing social science for nonmajors. American Journal of Business Education (Online), 7(2), 151-159.

Ketabi, S., \& Simm, I. S. (2009). Investigating Persian EFL teachers and learners' attitudes towards humor in class. International Journal of Language Studies, 3(4), 65-83.

Kher, N., Molstad, S., \& Donahue, R. (1999). Using humor in the college classroom to enhance teaching effectiveness in dread courses. College Student Journal, 33(3), 86-102. 


\section{International Journal of Research in English Education}

Lier, L. V. (2007). Action-based teaching, autonomy and identity. International Journal of Innovation in Language Learning and Teaching, 1(1), 46-65. http://dx.doi.org/10.2167/illt42.0

Long, D. L., \& Graesser, A. C. (1988). Wit and humor in discourse processing. Discourse Processes, 11(1), 35-60. http://dx.doi.org/10.1080/01638538809544690

Luo, J. J. (2004). Using DVD films to enhance college freshmen's English listening comprehension and motivation. Unpublished Master Thesis, National Tsing Hua University, Hsinchu. Taiwan, R.O.C.

Martin, R. A. (2007). The psychology of humor: An integrative approach. Elsevier Academic Press, Burlington, MA/London.

Mayer, R. E. (1999). Research-based principles for the design of instructional messages: The case of multimedia explanations. Document Design, 1, 7-20.

Mayer, R. E. (2008). Applying the science of learning: evidence-based principles for the design of multimedia instruction. American Psychologist, 63(8), 760-766.

Mayer, R. E. (2009). Multimedia learning (2nd ed). New York: Cambridge University Press.

Mayer, R. E. (2014). Research-based principles for multimedia learning. Retrieved from http://hilt.harvard.edu/event/richard-e-mayer-uc-santa-barbara

Medgyes, P. (2002). An introduction to foreign language learning and teaching. ELT Journal, 56(3), 333-335. doi: $10.2307 / 40264518$

Mekheimer, M. A. A. G. (2011). The impact of using videos on whole language learning in EFL context. Arab World English Journal, 2(2), 5-39.

Moreno, R., \& Mayer, R. E. (2007). Interactive multimodal learning environments. Educational Psychology Review, 19, 309-326.

Nazarian, S., \& Izadpanah, S. (2017). The study of the metalinguistic knowledge of English by students in an intensive and a traditional course. International Journal of English Linguistics, 7(1), $215-221$. doi: http://dx.doi.org/10.5539/ijel.v7n1p215

Neuliep, J. W. (1991). An examination of the content of high school teachers' humor in the classroom and the development of an inductively derived taxonomy of classroom humor. Communication Education, 40(4), 343355. http://dx.doi.org/10.1080/03634529109378859

Ormrod, J. E. (2014). Essentials of educational psychology: Big ideas to guide effective teaching. Pearson Higher Ed.

Paribakht, T. S., \& Wesche, M. (1996). Enhancing vocabulary acquisition through reading: A hierarchy of text-related exercise types. The Canadian Modern Language Review, 52(2), 155-178.

Rawlings, D. (2013). Humor preference and the Autism Quotient in an undergraduate sample. Humor, 26(3), 411421. doi: https://doi.org/10.1515/humor-2013-0028

Samson, A. C., \& Gross, J. J. (2012). Humor as emotion regulation: The differential consequences of negative versus positive humor. Cognition \& Emotion, 26(2), 375-384. doi: 10.1080/02699931

Schmidt, S. R., \& Williams, A. R. (2001). Memory for humorous cartoons. Memory \& Cognition, $29(2), 305-311$. doi: 10.3758/BF03194924

Schnotz, W. (2005). An integrated model of text and picture comprehension. The Cambridge handbook of multimedia learning, 49-69. doi: https://doi.org/10.1017/CBO9780511816819.005

Secules, T., Herron, C., \& Tomasello, M. (1992). The effect of video context on foreign language learning. Modern Language Journal, 76, 480-490.

Shahlou, P., \& Izadpanah, S. (2016). The study of relationship between EFL teacher's teaching context and their attitudes towards computer assisted language learning. The Social Sciences, 11(29), 7018-7024.

Sternberg, R. J. (1987). Most vocabulary is learned from context. In M. G. McKeown \& M. E. Curtis (Eds.), The nature of vocabulary acquisition (pp. 89-105). Hillsdale, NJ: Lawrence Erlbaum Associates. 


\section{International Journal of Research in English Education}

Tabatabaei, O., \& Gahroei, F. R. (2011). The contribution of movie clips to idiom learning improvement of Iranian EFL learners. Theory and Practice in Language Studies, 1(8), 990-1000.

Trachtenberg, S. (1979). Joke telling as a tool in ESL. TESOL Quarterly, 13, 89-99.

Wagner, M., \& Urios-Aparisi, E. (2011). The use of humor in the foreign language classroom: Funny and effective?. Humor-International Journal of Humor Research, 24(4), 399-434.

Withey, C. (2016). Using animations with students. The Legal Academic's Handbook, 42.

Ziyaeemehr, A., Kumar, V., \& Abdullah, M. S. F. (2011). Use and non-use of humor in academic ESL classrooms. English Language Teaching, 4(3), 111-123. doi:10.5539/elt.v4n3p111 